\title{
Анализ баланса финансовых потоков между центром и регионами в РФ 1
}

\begin{abstract}
В.В. КЛИМАНОВ, доктор экономических наук, Институт общественных наук РАНХиГС, АНО «Институт реформирования общественных финансов». E-mail: vvk@irof.ru
\end{abstract}

Д.А. ЕРЕМИНА, АНО «Институт реформирования общественных финансов». E-mail: dan@irof.ru

А.А. МИХАЙЛОВА, кандидат экономических наук, АНО «Институт реформирования общественных финансов», Институт общественных наук РАНХиГС, Москва. E-mail: aam@irof.ru

В статье рассматриваются сложившиеся особенности распределения «прямых» расходов федерального бюджета, на основе которых составляется баланс встречных финансовых потоков по регионам (в том числе с учетом численности населения) и выявляются регионы-«доноры». Определена степень участия регионов в формировании федерального и региональных бюджетов, показаны существенные различия между субъектами Федерации по концентрации налогов и доле финансовой помощи в их доходах.

Ключевые слова: субъекты Российской Федерации, региональные бюджеты, финансовые потоки, федеральные расходы, безвозмездные поступления, регионы-доноры, регионы-реципиенты

Очевидно, что в любом государстве регионы различаются между собой не только по показателям социально-экономического развития, но и по объемам средств, поступающих на территорию из федерального бюджета (в основном как межбюджетные трансферты). «Прямые» расходы федерального бюджета распределяются по регионам как в форме бюджетных инвестиций в рамках федеральной адресной инвестиционной программы, так и в виде текущего финансирования федеральных учреждений. В этой связи тема «донорства»/«реципиентства» субъектов Российской Федерации приобретает новое значение [Юшков и др., 2017].

Распространено мнение, что донорами являются регионы, которые не получают дотаций на выравнивание бюджетной обеспеченности из федерального бюджета [Климанов, Михайлова, 2016]. В такой ситуации их требования о предоставлении дополнительных доходных полномочий многим кажутся вполне

\footnotetext{
${ }^{1}$ Статья отражает часть результатов научно-исследовательской работы «Особенности применения дифференцированного подхода в регулировании регионального развития», выполняемой в рамках государственного задания РАНХиГС в 2018 г.
} 
закономерными [Экономика.., 2016]. При этом сокращение числа регионов-доноров в последние годы трактуется, с одной стороны, как признак ухудшения экономической ситуации в стране в целом, с другой - как свидетельство низкой эффективности системы государственных и муниципальных финансов [Региональная политика.., 2015].

Федеральные ассигнования, перечисляемые в форме «прямых» расходов на финансирование федеральных учреждений, мероприятий федеральных программ, выплату заработной платы работникам федеральной бюджетной сферы и т.д., не имеют отношения к региональным расходам, и по логике должны учитываться в качестве расходов федерального центра. Однако эти средства тратятся все же на территории конкретных субъектов Федерации и имеют для последних важное значение, как и ресурсы, поступающие по линии финансовой помощи [Федеральный бюджет..., 2001].

В конце 1990-х - начале 2000-х гг. коллективом авторов под руководством А. М. Лаврова была разработана методика анализа финансовых потоков между центром и регионами [Федеральный бюджет.., 1999; Федеральный бюджет.., 2001], в основе которой лежит учет не только лишь межбюджетных трансфертов из центра в регионы, но и всех исходящих и входящих потоков региональных бюджетов. Методика, к сожалению, не получила дальнейшего развития и при формировании современной системы разграничения полномочий и межбюджетных отношений не применялась.

Тем не менее составление такого сводного баланса потоков бюджетных средств из региона в регион очень важно как при определении реального финансового потенциала территории, так и направлений совершенствования собственно межбюджетных отношений и всего комплекса мер по регулированию регионального развития. При составлении баланса, адаптированного под изменившиеся условия, учитывались финансовые потоки двух противоположных направлений: доходов, поступающих на федеральный уровень с территории субъектов Федерации, и расходов, осуществляемых из федерального бюджета в регионах. Имеющие территориальную привязку доходы федерального бюджета делятся на налоговые и неналоговые.

Поступление большей части доходов в федеральный бюджет контролируется Федеральной налоговой службой России, через 
которую проходят все налоги. Однако для корректности учета мы использовали данные и территориальных органов Федерального казначейства, через которые также проходят как входящие, так и исходящие потоки региональных бюджетов. Таким образом, в составленном нами балансе финансовых потоков нашли отражение только собранные (а не начисленные) налоги и фактически профинансированные расходы федерального бюджета.

Баланс финансовых потоков по отдельным регионам характеризуют два общих показателя:

1) соотношение собранных на территории региона и зачисленных в федеральный бюджет доходов, с одной стороны, и расходов федерального бюджета на территории данного субъекта Федерации, включая финансовую помощь, с другой (назовем это процентом возврата средств на территорию);

2) разница между собранными на территории региона и зачисленными в федеральный бюджет доходами и расходами федерального бюджета на территории в расчете на душу населения (баланс в расчете на душу населения).

Первый показатель позволяет оценить масштабы «донорства» и «реципиентства» отдельных регионов, второй - характеризует масштабы зависимости регионов от перечислений из федерального бюджета (или, наоборот, федерального бюджета от их перечислений).

Формулы расчета названных показателей выглядят следующим образом:

$$
\begin{aligned}
& B_{\%}=[(F+P+R) /(D)] \cdot 100 \%,(1) \\
& B_{\mathrm{n}}=[(F+P+R)-(D)] / N,(2)
\end{aligned}
$$

где $B_{\%}$ - процент возврата по балансу, учитывающему как финансовую помощь региональным бюджетам, так и «прямые» расходы федерального бюджета;

$B_{\mathrm{n}}$ - баланс на душу населения, учитывающий как финансовую помощь региональным бюджетам, так и «прямые» расходы федерального бюджета;

$F$ - финансовая помощь региональным бюджетам (безвозмездные поступления в бюджеты субъектов Российской Федерации); $P$ - бюджетные ассигнования в рамках федеральной адресной инвестиционной программы в части средств, направленных на реализацию мероприятий и проектов на данной территории; $R$ - расходы федерального бюджета; 
$D$ - доходы федерального бюджета;

$N$ - численность населения региона.

С определенной долей условности можно считать, что, если процент возврата меньше 100 или баланс на душу населения отрицателен, регион может считаться донором федерального бюджета (отдает больше средств, чем получает), а если процент возврата больше 100 или баланс на душу населения положителен, регион - реципиент (отдает меньше, чем получает).

Использованные в предложенных формулах так называемые «прямые» расходы федерального бюджета в регионах рассчитаны в соответствии с информацией о кассовом поступлении и выбытии бюджетных средств территориальных управлений Федерального казначейства и представляют собой разницу общей суммы расходов федерального бюджета, поступающих на территорию, налоговых отчислений, поступающих в федеральный бюджет с территории конкретного региона, и бюджетных ассигнований на федеральную адресную инвестиционную программу.

Анализ проводился по итогам 2016 г. по 83 субъектам Российской Федерации. Республики Тыва и Адыгея пришлось из него исключить, так как соответствующая отчетность не представлена на сайтах управлений Федерального казначейства по данным регионам.

Помимо «прямых» расходов федеральный бюджет предоставляет регионам межбюджетные трансферты. В 2016 г. доля безвозмездных перечислений в региональные бюджеты в суммарной величине финансовой помощи и «прямых» расходах федерального бюджета по территориям варьировалась от 6\% в Москве до $57 \%$ в республиках Алтай и Дагестан.

Что касается регионов с низкой долей безвозмездных перечислений относительно общей суммы федеральных расходов в 2016 г., то в Мурманской области она составляла 7\% от совокупных доходов региона, в Ямало-Ненецком АО - 9\%, в Санкт-Петербурге $-10 \%$, т.е. львиная доля федеральных расходов на данной территории идет не в форме трансфертов, а путем прямого финансирования объектов и учреждений там из федерального бюджета.

Процент возврата по балансу финансовых потоков, учитывающий как финансовую помощь региональным бюджетам, так и прямые расходы федерального бюджета (формула 1), в 2016 г. варьировался от 3\% в Ханты-Мансийском АО - Югра до 4929\% 
в Республике Ингушетия. В среднем по России данный показатель составил 77\%, что подтверждает тот факт, что финансовые потоки перетекают больше в центр, чем возвращаются обратно.

Если сравнить регионы по проценту возврата средств по балансу финансовых потоков в 1999 г. и 2016 г., то видно, что этот показатель сильно варьируется не только по отдельным регионам, но и во времени. Например, доля возврата по Республике Ингушетия изменилась со $120 \%$ в 1999 г. до 4929\% по итогам 2016 г. В 1999 г. самые большие федеральные ассигнования получили Республика Дагестан (1618\%) и Чукотский АО (1349\%). Спустя 17 лет их позиции составили соответственно 1067\% и 537\%. Существенно поменяли позиции Иркутская область (где доля возврата упала с 566\% до 67\%) и Красноярский край (доля возврата упала со $167 \%$ до 50\%).

Различия между регионами по степени их «донорства» и «реципиентства» в целом соответствуют сложившимся представлениям о финансово сильных и слабых регионах. Минимальный процент возврата из федерального бюджета характерен для нефтегазодобывающих автономных округов и крупных экономически развитых субъектов РФ (Ханты-Мансийского, Ямало-Ненецкого и Ненецкого АО, Тюменской, Сахалинской, Оренбургской, Ленинградской областей, республик Коми и Татарстан, г. Санкт-Петербурга). Исключением оказалась Москва, которая как много отдает в федеральный бюджет, так и получает обратно (72\%). В число же «глубоких» реципиентов в основном попадают республики Северо-Кавказского федерального округа и некоторые дальневосточные регионы.

Подобная зависимость подтверждается и статистически: процент возврата средств в значительной степени зависит от доли финансовой помощи в доходах региональных бюджетов. Так, Республика Крым, получая $1170 \%$ средств федерального бюджета по отношению к собранным на собственной территории налогам в федеральный бюджет, получает в качестве межбюджетных трансфертов $65 \%$ доходов регионального бюджета. Схожая ситуация у Республики Дагестан и Камчатского края. Бюджет Пензенской области на треть состоит из безвозмездных поступлений и при этом получает «из центра» почти в четыре раза больше, чем отдает (390\% «возврата»). В то же время ЯмалоНенецкий АО возвращает лишь 5\% от собранных с территории 
налогов, доля безвозмездных поступлений в его доходах составляет всего 2\% (как и у Ханты-Мансийского АО). Фактически данные регионы безвозмездно «кормят» федеральный бюджет.

Если посмотреть на баланс финансовых потоков, то есть на разницу между собранными на территории региона и зачисленными в федеральный бюджет доходами и расходами федерального бюджета на территории, то по итогам 2016 г. регионами-«донорами» могут считаться 22 из 83 субъектов Российской Федерации. Однако тот факт, что, согласно нашим расчетам, 75\% российских регионов попадают в число реципиентов, означает, что даже если в их бюджетах будут оставаться все налоги и сборы, собираемые на данной территории и поступающие в настоящее время в бюджеты разных уровней, без дополнительной финансовой помощи из центра им все равно не будет хватать налоговых и неналоговых доходов для покрытия собственных расходных обязательств. Таким образом, установление дифференцированных нормативов зачисления налогов в региональные бюджеты, которое нередко предлагается в качестве одного из вариантов реформирования системы межбюджетных отношений в России, не сможет полностью решить проблему «реципиентства».

Максимальные финансовые потоки в 2016 г. (более 100 млрд руб.) были перечислены от Республики Татарстан, Красноярского края, Оренбургской и Самарской областей. Абсолютными же регионами-«донорами» являются Ханты-Мансийский АО - Югра, Ямало-Ненецкий АО, г. Москва и г. СанктПетербург. Минимальную помощь от федерального бюджета относительно остальных регионов и регионов-«доноров» соответственно получают Волгоградская, Смоленская и Омская области от (3 до 5 млн руб. в год). Таким регионам, как Республика Крым, Краснодарский край, Республика Дагестан и Чеченская Республика, наоборот, было предоставлено из федерального бюджета от 100 до 200 млрд руб.

Баланс финансовых потоков с учетом численности населения в регионе может более корректно отражать экономическое положение региона. В среднем с учетом взаимных финансовых потоков по стране 13855 руб. в расчёте на одного человека поступает из регионов в федеральный бюджет за год. Первыми в списке регионов-«доноров» согласно балансу на душу населения стоят Ненецкий АО, отдающий в федеральный бюджет 1,35 млн руб. 
на человека, Ямало-Ненецкий АО (почти 1,3 млн руб.), ХантыМансийский АО - Югра (880 тыс. руб.).

Безусловно, сравнивать финансовые потоки 1999 г. в абсолютном выражении с потоками 2016 г. не совсем корректно, тем не менее можно говорить, что общие тенденции сохранились. Так, например, Ямало-Ненецкий АО и Ханты-Мансийский АО Югра также лидировали в 1999 г. по балансу на душу населения, отдавая в федеральный бюджет 21,1 тыс. руб. и 21,5 тыс. руб. соответственно. Однако Ненецкий АО, в котором только в последние десятилетия началась активная добыча нефти, в 1999 г. отдавал всего лишь 126 руб. против 1,35 млн руб. в 2016 г. То же касается и регионов-«аутсайдеров», которые сильно выделяются на фоне остальных субъектов Российской Федерации, среди них Чукотский АО и Камчатский край (ранее- область с автономным округом), которые получали от федерального бюджета в 1999 г. 25,1 тыс. руб. и 23,2 тыс. руб. соответственно на человека. Среди регионов, кардинально изменивших свое положение за 17 лет, есть Сахалинская область, которая больше получала в 1999 г., а в 2016 г. стала регионом-«донором», отдав 1442 руб. с одного жителя.

Что касается соотношения объема федеральных расходов (включая «прямые» расходы и безвозмездные поступления из федерального бюджета) к налоговым доходам консолидированного бюджета субъекта Российской Федерации, то в среднем по России этот показатель составил по итогам 2016 г. 90\%, что свидетельствует о том, что прямая безвозмездная финансовая помощь Федерации находится практически на уровне налоговых доходов регионов.

Группировка регионов по соотношению расходов федерального бюджета в субъекте Федерации к налоговым доходам консолидированного бюджета региона в 2016 г. выглядит следующим образом (табл. 1). Согласно расчетам, более $12 \%$ населения (18,1 млн чел.) проживает в относительно самостоятельных регионах, где указанное соотношение составляет менее $50 \%$, и около $45 \%$ (66 млн чел.) - в регионах, где данный показатель составляет от 50 до $100 \%$. Чуть более четверти населения проживает в регионах, где объем расходов из федерального бюджета превышает налоговые доходы, собранные там, до двух раз. В сильно зависимых регионах (от 200 до 500\%) проживает менее 8\% населения страны (11,3 млн чел.), но в шести регионах с высокой зависимостью (соотношение 5-15 раз) проживает 22,8 млн населения (или 16,6\%). 


\section{Таблица 1. Группировка регионов по соотношению расходов федерального бюджета в субъекте Федерации к налоговым доходам консолидированного бюджета региона в 2016 г.}

\begin{tabular}{|c|c|c|}
\hline $\begin{array}{l}\text { Соотно- } \\
\text { шение, \% }\end{array}$ & Регион & Население \\
\hline Менее 50 & $\begin{array}{l}\text { Самарская обл., Республика Татарстан, Тюменская, Омская, Орловская, } \\
\text { Ленинградская, Ярославская области, Ненецкий АО, Сахалинская обл., } \\
\text { Ямало-Ненецкий АО, Ханты-Мансийский АО - Югра, Липецкая обл. }\end{array}$ & $\begin{array}{l}18,1 \text { млн чел. } \\
(12,4 \%)\end{array}$ \\
\hline $50-100$ & $\begin{array}{l}\text { Белгородская, Саратовская, Владимирская, Волгоградская, Курская, } \\
\text { Воронежская области, г. Москва, Челябинская, Свердловская, Ке- } \\
\text { меровская, Оренбургская, Томская, Новосибирская, Астраханская, } \\
\text { Нижегородская, Иркутская, Тульская области, Удмуртская Республика, } \\
\text { Красноярский кр., Республика Башкортостан, Костромская область, } \\
\text { г. Санкт-Петербург, Пермский кр., Республика Коми }\end{array}$ & $\begin{array}{l}66,0 \text { млн чел. } \\
(45,5 \%)\end{array}$ \\
\hline $100-200$ & $\begin{array}{l}\text { Забайкальский кр., Чукотский АО, Курганская обл., Республика Мордо- } \\
\text { вия, Чувашская Республика, Ставропольский кр., Краснодарский кр., } \\
\text { Республика Марий-Эл, Мурманская обл., Алтайский кр., Амурская, } \\
\text { Пензенская, Кировская, Новгородская, Ивановскаяобласти, Хабаровский } \\
\text { кр., Тамбовская, Архангельская, Рязанская, Магаданская области, } \\
\text { Приморский кр., Республика Хакасия, Вологодская, Смоленская, } \\
\text { Ульяновская, Ростовская, Тверская области, Республика Саха (Якутия) }\end{array}$ & $\begin{array}{l}38,5 \text { млн чел. } \\
(26,3 \%)\end{array}$ \\
\hline $200-500$ & $\begin{array}{l}\text { Республика Дагестан, Карачаево-Черкесская Республика, Республика } \\
\text { Калмыкия, Калининградская обл., РеспубликаСевернаяОсетия-Алания, } \\
\text { Камчатский кр., Калужская обл., Кабардино-Балкарская Республика, } \\
\text { Брянская обл., Еврейская автономная обл., Республика Карелия, } \\
\text { Псковская обл., Республика Бурятия }\end{array}$ & $\begin{array}{l}11,3 \text { млн чел. } \\
(7,7 \%)\end{array}$ \\
\hline $500-1500$ & $\begin{array}{l}\text { Республика Ингушетия, Московская обл., Чеченская Республика, } \\
\text { Республика Крым, Республика Алтай, г. Севастополь }\end{array}$ & $\begin{array}{l}22,8 \text { млн чел. } \\
(16,6 \%)\end{array}$ \\
\hline
\end{tabular}

Соотношение налоговых отчислений в федеральный бюджет к налоговым доходам консолидированного бюджета субъекта Федерации составило в 2016 г. в среднем по стране 91\%, в Центральном федеральном округе - 59\%, Северо-Западном - $100 \%$, Северо-Кавказском - 38\%, Южном - 55\%, Приволжском - 91\%, Уральском - 284\%, в Сибирском федеральном округе - $62 \%$.

Что касается налоговой структуры федерального бюджета в целом, то ощутимая разница между регионами России по численности населения и уровню экономического развития является причиной того, что поступления из малого числа регионов образовывают значительную часть налоговых доходов федерального бюджета (табл. 2). В 2016 г. наибольшая доля налогов в федеральном бюджете приходилась на Ханты-Мансийский АО - Югра (21\%). Доля первых пяти регионов, к которым также относятся Москва, Ямало-Ненецкий АО, Санкт-Петербург, Московская область, составляет 58\%. Первые 10 регионов составили $70 \%$. 
В целом, в 2016 г. 21 субъект Российской Федерации отдавал свыше $1 \%$ своих налоговых доходов в федеральный бюджет, в то время как 23 региона отдавали лишь менее $0,1 \%$ каждый. Из-за возмещения налога на добавленную стоимость и иных особенностей учета некоторые регионы имели отрицательные показатели доли налоговых поступлений в федеральный бюджет. К числу таких регионов в 2016 г. относились Чукотский $\mathrm{AO}$, Республика Бурятия, Тульская область, Чеченская Республика, Липецкая и Магаданская области.

\section{Таблица 2. Характеристики налоговых поступлений в федеральный бюджет с территорий отдельных регионов в 2016 г.}

\begin{tabular}{|c|c|c|}
\hline Показатель & $\begin{array}{l}\text { Значение } \\
\text { показа- } \\
\text { теля, \% }\end{array}$ & Субъект Российской Федерации \\
\hline Доля региона-лидера & 21 & Ханты-Мансийский АО - Югра \\
\hline $\begin{array}{l}\text { Доля первых пяти } \\
\text { регионов }\end{array}$ & 58 & $\begin{array}{l}\text { Ханты-Мансийский АО - Югра + } \\
\text { г. Москва, Ямало-НенецкийАО, г. Санкт-Петербург, Московская обл. }\end{array}$ \\
\hline $\begin{array}{l}\text { Доля первых } 10 \\
\text { регионов }\end{array}$ & 70 & $\begin{array}{l}\text { Первые } 5 \text { регионов + } \\
\text { Республика Татарстан, Красноярский кр., Самарская обл., Орен- } \\
\text { бургская обл., Пермский кр. }\end{array}$ \\
\hline $\begin{array}{l}\text { Число регионов, доля } \\
\text { которых в налогах } \\
\text { федерального бюд- } \\
\text { жета более } 1 \%\end{array}$ & 21 & $\begin{array}{l}\text { Первые } 10 \text { регионов + } \\
\text { Ленинградская обл., Иркутская обл., Республика Башкортостан, } \\
\text { Краснодарский кр., Томская обл., Удмуртская Республика, } \\
\text { Республика Коми, Тюменская, Свердловская, Саратовская, } \\
\text { Челябинская области }\end{array}$ \\
\hline $\begin{array}{l}\text { Число регионов, доля } \\
\text { которых в налогах } \\
\text { федерального } \\
\text { бюджета менее 0,1\% } \\
\text { (в том числе отрица- } \\
\text { тельные значения) }\end{array}$ & 29 & $\begin{array}{l}\text { Ивановская, Костромская, Архангельская области, Республика } \\
\text { Марий-Эл, Орловская обл., Новгородская обл., Тамбовская обл., } \\
\text { Кабардино-Балкарская Республика, Камчатский кр., Республика } \\
\text { Карелия, Республика Северная Осетия - Алания, г. Севастополь, } \\
\text { Республика Адыгея, Амурская обл., Псковская обл., Карачаево- } \\
\text { Черкесская Республика, Республика Алтай, Республика Хакасия, } \\
\text { Республика Калмыкия, Республика Ингушетия, Еврейская авто- } \\
\text { номная обл., Республика Тыва, Забайкальский кр., Чукотский } \\
\text { АО, Республика Бурятия, Тульская обл., Чеченская Республика, } \\
\text { Липецкая обл., Магаданская обл. }\end{array}$ \\
\hline
\end{tabular}

Интересно выявить и степень зависимости субъектов Федерации от финансовой помощи из федерального бюджета. Различия между регионами по доле в их доходах финансовой помощи существенны [Яговкина, Недопивцева, 2016]. В 2016 г. доля безвозмездных поступлений в доходах региональных бюджетов составила в среднем 16\%. Наибольшую долю безвозмездных поступлений можно отметить в Республике Ингушетия (86\%), Чеченской Республике (78\%), Республике Тыва (76\%) и Республике 
Алтай (70\%), Республике Дагестан (66\%), Республике Крым (65\%), а наименьшую - в Московской области (5\%), Санкт-Петербурге (5\%), Ханты-Мансийском АО - Югра (4\%), Москве (4\%), Сахалинской области (3\%) и Ямало-Ненецком АО (2\%). Москва, которая в 1999 г. формально вообще не получала финансовую помощь, в 2016 г. продолжала иметь наименьшую долю безвозмездных поступлений в доходах бюджета - всего 4\%. В 1999 г. в Республиках Башкортостан и Татарстан, Ханты-Мансийском и Ямало-Ненецком $\mathrm{AO}$, Самарской, Пермской областях и Санкт-Петербурге она также не превышала 1\% доходов региональных бюджетов, а в 2016 г. показатели варьировались от 2 до $18 \%$.

Таким образом, финансовые потоки являются инструментом разграничения финансовых полномочий между центром и регионами [Климанов и др., 2013]. Методика расчета баланса финансовых потоков между федеральным центром и регионами, раскрывающая полное представление о финансовых взаимоотношениях органов государственной власти разного уровня, должна стать основой системы федерального слежения, анализа и прогнозирования ситуации в регионах.

Проведенные расчёты показывают, что при таком понимании в России больше регионов-«доноров», нежели когда в соответствии с положениями бюджетного законодательства донорами считаются регионы с уровнем расчетной бюджетной обеспеченности выше установленного критерия выравнивания расчетной бюджетной обеспеченности субъектов РФ. В 2016 г. в числе регионов-«доноров», то есть тех, кто не получал дотации, было 14 субъектов РФ. В то же время очевидно, что поступающие в федеральный бюджет налоги также локализованы, а потому число регионов, с территории которых в федеральный бюджет направляются финансовые средства, значительно больше: практически все регионы в таком случае будут являться «донорами».

Согласно же полученным в исследовании данным число регионов-доноров по проценту возврата средств по балансу финансовых потоков, а также согласно самому балансу финансовых потоков, учитывающему прямые расходы федерального бюджета, достигло 22. Причем десять из них не являются регионами«донорами» в общепринятом смысле, однако согласно предлагаемой методике Красноярский край, Оренбургская область, Пермский край, Республика Коми, Республика Башкортостан, 
Томская область, Удмуртская Республика, Иркутская, Астраханская и Саратовская области таковыми являются, а вот Калужская и Свердловская - нет.

Сохраняющийся субъективизм в принятии решения в отношении регулирования или прямого установления тех или иных направлений финансовых потоков из федерального бюджета в региональные и наоборот свидетельствует о необходимости дальнейшего совершенствования межбюджетных отношений в РФ [Лавров, 2005; Михайлова и др., 2018]. В этой связи описанная методика расчета общего баланса финансовых потоков бюджетных средств для каждого региона может стать основой для принятия тех или иных индивидуальных решений по отношению к конкретному субъекту Федерации при предоставлении, например, целевых субсидий или иных межбюджетных трансфертов. Такие меры в свою очередь станут одним из инструментов внедрения новых принципов дифференцированного подхода в регулировании регионального развития.

\section{Литература}

Климанов В.В., Алтынцев А.В., Михайлова А.А., Яговкина В.А. Анализ исполнения в регионах переданных обязательств Российской Федерации // Государственный аудит. Право. Экономика. 2013. № 2. С. 67-72.

Климанов В.В., Михайлова А.А. Бюджеты высокодотационных субъектов Российской Федерации: меры по обеспечению сбалансированности // Вестник АКСОР. 2016. № 1. С. 76-83.

Лавров А. М. Бюджетная реформа в России. От управления затратами к управлению результатами. 2005. М.: КомКнига. 556 с.

Михайлова А.А., Климанов В.В., Сафина А.И. Влияние межбюджетных трансфертов на экономический рост и структуру региональной экономики // Вопросы экономики. 2018. № 1. С. 91-103.

Региональная политика: зарубежный опыт и российские реалии /Под ред. А. В. Кузнецова, О.В. Кузнецовой. М.: ИМЭМО РАН, 2015. 137 с.

Федеральный бюджет и регионы: структура финансовых потоков /Под ред. А.М. Лаврова. Институт «Восток-Запад». М.: МАКС Пресс, 2001. 311 с.

Федеральный бюджет и регионы: Опыт анализа финансовых потоков / Московский центр Института «Восток-Запад». М.: МАКС Пресс, 1999. 288 с.

Экономика общественного сектора /Под ред. Л.И. Якобсона, М. Г. Колосницыной. 3-е изд., перераб. и доп. М.: Юрайт, 2016. 588 с.

Юиков А., Одинг Н., Савулькин Л. Судьбы российских регионов-доноров // Вопросы экономики. 2017. № 9. С. 63-82.

Яговкина В.А., Недопивиева Д. А. Систематизация межбюджетных трансфертов в бюджеты Российской Федерации в 2005-2015 гг. // Общественные финансы. 2016. № 2 (33). С. 73-97. 


\section{Summary}

Klimanov V.V., Institute for Social Sciences (RANEPA), Institute for Public Finance Reform, Eremina D.A., Institute for Public Finance Reform, Mikhaylova A.A., Institute for Public Finance Reform, Institute for Social Sciences (RANEPA), Moscow

Analysis of the Balance of Financial Flows Between the Center and Regions in the Russian Federation

The article considers the existing peculiarities of the allocation of "direct" expenditures from the State budget, that underpin the balance of colliding financial flows in Russian regions (also in the light of account the population) and thus real donor regions are identified. It determines the region's participation rate in the State (federal) and territorial budgeting, shows stark regional disparities in terms of taxes concentration and the share of financial assistance in their incomes.

Subjects of the Russian Federation; regional budgets; financial flow; federal expenditures; gratuitous receipts; donor regions; recipient regions

\section{References}

Klimanov V.V., Altyncev A.V., Mikhaylova A.A., Yagovkina V.A. (2013). Analiz ispolneniya v regionah peredannyh obyazatel'stv Rossijskoj Federacii. Gosudarstvennyj audit. Pravo. Ehkonomika. [State Audit. Law. Economics]. No. 2. Pp. 67-72. (In Russ.)

Klimanov V.V., Mikhaylova A.A. (2016). Byudzhety vysokodotacionnyh sub"ektov Rossijskoj Federacii: mery po obespecheniyu sbalansirovannosti. Vestnik AKSOR [AKSOR Bulletin]. No. 1. Pp. 76-83. (In Russ.)

Lavrov A. M. (2005). Byudzhetnaya reforma v Rossii: ot upravleniya zatratami k upravleniyu rezul'tatami. Moscow, Komkniga Publ. 556 p. (In Russ.)

Mikhaylova A.A., Klimanov V.V., Safina A. I. (2018). Vliyanie mezhbyudzhetnyh transfertov na ehkonomicheskij rost i strukturu regional'noj ehkonomiki. Voprosy Ekonomiki. [Questions of economics]. No.1. Pp. 91-103. (In Russ.)

Regional'naya politika: zarubezhnyj opyt i rossijskie realii. (2015). Moscow, IMEMO RAN Publ. 137 p. (In Russ.)

Federal'nyj byudzhet i regiony: struktura finansovyh potokov. (2001). Institut Vostok-Zapad. Moscow, MAKS Press Publ. 311 p. (In Russ.)

Federal'nyj byudzhet i regiony: Opyt analiza finansovyh potokov. (1999). Moskovskij centr Instituta «Vostok-Zapad». Moscow, MAKS-PRESS Publ. 288 p. (In Russ.)

Ekonomika obshchestvennogo sektora. (2016). Moscow, YUrajt Publ. 588 p. (In Russ.)

Yushkov A., Oding N., Savul'kin L. (2017) Sud'by rossijskih regionov-donorov. Voprosy Ekonomiki. [Questions of Economics]. No. 9. Pp. 63-82. (In Russ.)

Yagovkina V.A., Nedopivceva D.A. (2016). Sistematizaciya mezhbyudzhetnyh transfertov v byudzhety Rossijskoj Federacii v 2005-2015 gg. Obshchestvennye finansy [Public Finance]. No. 2 (33). Pp. 73-97. (In Russ.) 